\title{
Experimental Demonstration of Localized Excess Protons at a Water- Membrane Interface
}

\section{Haitham A. Saeed and James W. Lee*}

Department of Chemistry and Biochemistry, Old Dominion University, Norfolk, VA 23529, USA

\begin{abstract}
The widespread Mitchellian proton motive force equation has recently been revised with the proton-electrostatics localization hypothesis, which, for the first time, successfully elucidates the 30-year longstanding energetic conundrum of ATP synthesis in alkalophilic bacteria. To demonstrate the fundamental behavior of localized protons in a pure watermembrane-water system in relation to the newly derived pmf equation, excess protons and excess hydroxyl anions were generated by utilizing an "open-circuit" water-electrolysis system and their distributions were tested using a protonsensing aluminum membrane. The proton-sensing film placed at the membrane-water interface displayed dramatic localized proton activity while that placed into the bulk water phase showed no excess proton activity during the entire experiment. These observations clearly match with the prediction from the proton-electrostatics localization hypothesis that excess protons do not stay in water bulk phase; they localize at the water-membrane interface in a manner similar to the behavior of excess electrons in a conductor. This finding has significance not only in the science of bioenergetics but also in the fundamental understanding for the importance of water to life in serving as a proton conductor for energy transduction in living organisms.
\end{abstract}

Keywords: Proton-electrostatic localization; Localized excess protons; Proton capacitor at water-membrane interface; Corrected pmf equation; Bioenergetics; Importance of water to life

\section{Introduction}

Peter Mitchell's work on his chemiosmotic theory [1-3] won the 1978 Nobel prize in chemistry and his bioenergetics (proton motive force) equation since then was introduced into many textbooks [4-6]. One of the forms of the Mitchellian bioenergetics equation is expressed as free energy difference $\Delta \tilde{\mu} \mathrm{H}^{+}$(also known as the Gibbs energy change $(\Delta \mathrm{G}))$ for protons across a biological membrane including a term for the concentration difference and a term for the electrical potential:

$$
\Delta \tilde{\mu} \mathrm{H}^{+}=\Delta \mathrm{G}=\mathrm{RT} \ln \frac{\left[\mathrm{C}_{2}\right]}{\left[\mathrm{C}_{1}\right]}+\mathrm{ZF} \Delta \psi
$$

Where $\mathrm{C}_{1}$ and $\mathrm{C}_{2}$ are the proton concentrations on the two sides of the membrane, $\mathrm{Z}$ is the charge on a proton ( 1 for a proton), $\mathrm{F}$ is the Faraday's constant, $\Delta \Psi$ electrical potential difference across the membrane, $\mathrm{R}$ is the gas constant, and $\mathrm{T}$ is the absolute temperature.

This Mitchellian equation (1), sometimes, is written also as the equation for the proton motive force (pmf) $\Delta \mathrm{p}$ that drives the protons through the ATP synthase:

$$
\text { pmf }(\Delta p)=-\Delta \tilde{\mu} H^{+} / F=\Delta \psi-2.3 R T / F \times \Delta p H
$$

Where $\Delta \mathrm{pH}$ is the $\mathrm{pH}$ difference between the two bulk aqueous phases separated by the membrane.

From equation (1), one can clearly see that Mitchell treated the protons as solutes such as sugar molecules that are delocalized and can stay everywhere in the bulk aqueous phase. Consequently, the Mitchellian delocalized proton-coupling view is that the ATP synthase is coupled to the redox proton pumps via bulk phase-to-bulk phase proton electrochemical potential gradients generated across the biological membrane; while the membrane is regarded as an insulator between the two bulk phases that plays no role in the lateral transduction of the protons to the ATP synthase.

The chemiosmotic theory was a major milestone in the history of bioenergetics when the early bioenergeticists including the "metabolic enzymologists" were still using substrate-level phosphorylation as a model to seek some kind of "chemical coupling" for "phosphorylated intermediate" with "energy-rich" squiggle $(\sim)$ bonds [3,7]. The chemiosmotic theory provided a revolutionary concept that the enigmatic link between electrogenic proton pumps and a protontranslocating ATP synthase is a proton gradient across the membrane [8]. Its revolutionary significance or influence to the field of bioenergetics could be hardly overstated, which is almost something like the Schrodinger equation to the modern quantum mechanics. It generated continuous discussions and sometimes heated debates that energized the entire field of bioenergetics. As a result, biochemists can now understand the biological energy transduction processes far better than before the era of the chemiosmotic theory [8].

However, the question of whether the proton pathway is delocalized throughout the bulk aqueous volume or is localized at its membrane surface has remained open to discussion since it was first raised in 1961 by Williams [9-13]. He [14] rightly pointed out the deficiency of the Mitchellian delocalized proton-coupling view by stating: "If charge is thrown out into the medium, as in osmotic theories, then we face the problem of equilibration of the energy of single cell on its outside with the whole of the volume in which it is suspended, say the Pacific Ocean."

This statement made by Williams 40 years ago remains as a valid criticism to the Mitchellian chemiosmotic theory even of today.

*Corresponding author: James W. Lee, Department of Chemistry and Biochemistry, Old Dominion University, Norfolk, VA 23529, USA, Tel: (757) 683 4260; Fax: (757) 683-5310; E-mail: jwlee@odu.edu

Received August 24, 2015; Accepted September 09, 2015; Published September 29, 2015

Citation: Saeed HA, Lee JW (2015) Experimental Demonstration of Localized Excess Protons at a Water-Membrane Interface. Bioenergetics 4: 127. doi:10.4172/2167-7662.1000127

Copyright: (c) 2015 Saeed HA, et al. This is an open-access article distributed under the terms of the Creative Commons Attribution License, which permits unrestricted use, distribution, and reproduction in any medium, provided the original author and source are credited. 
Unfortunately, probably because of the "Storm and Stress" period in the history of bioenergetics where the debates among disjunctive factions of bioenergeticists were so fiercely that the opposing parties with such deep emotions apparently lost the ability to objectively consider the other's points including Williams' "Pacific Ocean" arguments [15]. Hopefully, our new generation of scientists who are not emotionally attached with any of the opposing factions and bear none of the historical baggage will be able to restore the scientific civility and help move the field forward. Let's think about a bacterial cell growing in liquid culture medium in a flask. It is known that bacterial cell membrane is energized by pumping protons across the cellular membrane from the inside to the outside of the cell, which creates a proton motive force across the membrane. However, according to the Mitchellian equation (1 or 2) to create a proton motive force across the membrane, the bacterial cell in a liquid culture flask would have to cause a bulk-phase $\mathrm{pH}$ change in the entire volume of its liquid culture medium?, which physically is really impossible. From here, we can also understand that there is something really wrong in the Mitchellian equation (1 and 2) since it does not fit with the known physical reality here.

Perhaps, the most well-established scientific observations that showed the failure of the Mitchellian delocalized proton view are in alkalophilic bacteria, such as Bacillus pseuodofirmus [16-18]. These bacteria keep their internal $\mathrm{pH}$ about $2.3 \mathrm{pH}$ units more acidic than the ambient bulk pH 10.5, while $\Delta \psi$ is about $180 \mathrm{mV}$ in the direction from outside across the cellular membrane to the cytoplasm [19-21]. The application of Eq. 2 in this case would yield a pmf $(\Delta p)$ value so small ( $44.3 \mathrm{mV}$ at $\mathrm{T}=298 \mathrm{~K})$ that it has remained as a mystery for the last three decades as to how these organisms can synthesize ATP [22-24].

This long-standing unresolved energetic conundrum [25,26] can now be explained by the proton-electrostatics localization hypothesis [27]. Recently, Lee (one of us) has further elaborated his protonelectrostatics localization hypothesis and derived the following new proton motive force (pmf) equation [28]:

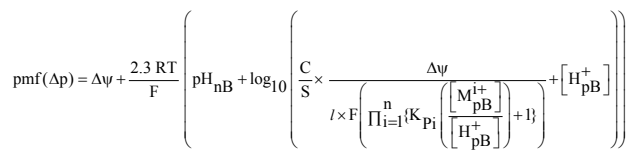

Where $\Delta \psi$ is the electrical potential difference across the membrane; $\mathrm{pH}_{\mathrm{nB}}$ is $\mathrm{pH}$ of the cytoplasmic bulk phase; $\left[\mathrm{H}^{+}{ }_{\mathrm{p}}\right]$ is the proton concentration in the periplasmic bulk aqueous phase; $\mathrm{C} / \mathrm{S}$ is the specific membrane capacitance; $l$ is the thickness for localized proton layer; $\mathrm{K}_{\mathrm{Pi}}$ is the equilibrium constant for non-proton cations $\left(\mathrm{M}_{\mathrm{pB}}^{\mathrm{i}}\right)$ to exchange for localized protons; and $\left[\mathrm{M}^{\mathrm{i}+}{ }_{\mathrm{pB}}\right]$ is the concentration of nonproton cations in liquid culture medium.

The use of this newly derived equation has recently yielded an overall pmf $(\Delta \mathrm{p})$ value $(215 \sim 233 \mathrm{mV})$ that is 4 times more than that $(44.3 \mathrm{mV})$ calculated from the Mitchellian equation for the alkalophilic bacteria growing at $\mathrm{pH} 10.5$ [28]. This newly calculated value is sufficient to overcome the observed phosphorylation potential $\Delta \mathrm{Gp}$ of $-478 \mathrm{mV}$ to synthesize ATP in the bacteria. Therefore, the 30 -yearlongstanding bioenergetics conundrum in alkalophilic bacteria has now, for the first time, been successfully elucidated as how they are able to synthesize ATP.

The core concept of the proton-electrostatics localization hypothesis is built on the premise that a water body, such as the water within a bacterial cell, can act as a proton conductor in a manner similar to an electric conductor with respect to the electrostatic behavior and charge conduction. This is consistent with the well-established knowledge that protons can quickly transfer among water molecules by the "hops and turns" mechanism that has been first outlined by Grotthuss two centuries ago [29-31]. By applying Gauss Law equation to a water-membrane-water system, it was found mathematically that the excess protons are localized at the water-membrane interface, forming a proton-capacitor-like structure: the localized excess protons-membrane-anions system [28]. Therefore, we may use the proton capacitor concept to calculate the effective concentration of the localized protons $\left[\mathrm{H}_{\mathrm{L}}^{+}\right]^{0}$ at the membrane-water interface in a pure water-membrane-water system assuming a reasonable thickness $(l)$ for the localized proton layer using the following equation:

$$
\left[\mathrm{H}_{\mathrm{L}}^{+}\right]^{0}=\frac{\mathrm{C}}{\mathrm{S}} \times \frac{\Delta \psi}{l \times \mathrm{F}}=\frac{\Delta \psi \cdot \kappa \cdot \varepsilon_{\mathrm{o}}}{\mathrm{d} \cdot l \times \mathrm{F}}
$$

Where $\mathrm{C} / \mathrm{S}$ is the membrane capacitance per unit surface area; $\mathrm{F}$ is the Faraday constant; $\kappa$ is the dielectric constant of the membrane; $\varepsilon$ is the electric permittivity; $d$ is the thickness of the membrane; and $l$ is the thickness of the localized proton layer.

This proton-capacitor equation (4) is a key component for the revised pmf equation (3), which has an additional term that accounts for the effect of non-proton cations exchanging with the localized protons. An experimental demonstration of the proton capacitor concept with a pure water-membrane-water system in relation to Equation 4 is fundamentally important to testing the protonelectrostatics localization hypothesis. In this article, we report our recent experimental study in which the distribution of localized excess protons at a water-membrane interface was demonstrated for the first time.

\section{Materials and Methods}

\section{Excess protons generation}

Two ElectroPrep electrolysis systems (Cat no. 741196) purchased from Harvard Apparatus Inc. were used with one of them as a control. Each of these ElectroPrep electrolysis systems (Figure 1) comprised a cathode chamber, a small Teflon center chamber and an anode chamber. The small Teflon center chamber was inserted to the middle of the inter-chamber wall that separates the cathode and anode water chambers. To test the proton capacitor concept predicted by the proton-electrostatics localization hypothesis, a $25-\mu \mathrm{m}$ thick aluminum membrane (Al) was sandwiched in between two pieces of impermeable $75-\mu \mathrm{m}$ thick Teflon $(\mathrm{Tf})$ membrane (all with a diameter of $2.35 \mathrm{~cm}$ ), forming a Tf-Al-Tf membrane as shown in Figures 1, 2a and $2 \mathrm{~b}$.

\section{Bulk-phase water $\mathrm{pH}$ measurement}

After the Teflon center chamber was placed into the inter-chamber wall, the two compartments of each ElectroPrep electrolysis system were filled with ultrapure MilliQ-deionized water (Millipore, 18.2 $\mathrm{M} \Omega . \mathrm{cm}$ at $22.5^{\circ} \mathrm{C}$ ): $300 \mathrm{ml}$ in the cathode chamber and about $600 \mathrm{ml}$ in the anode chamber rendering an equal water level in both chambers (Figure 1). The bulk phase $\mathrm{pH}$ of the deionized water was measured using Inlab pure pro ISM $\mathrm{pH}$ probe (Mettler Toledo) in a small beaker at the beginning and in the anode and cathode chambers at the end of each 10-hour experiment.

\section{Detection of localized excess protons with a proton-sensing film}

Aluminum membrane (proton-sensing film) purchased from VWR was cut into round disks with a diameter of $2.35 \mathrm{~cm}$. A Teflon 
membrane disk $\left(\mathrm{T}_{\mathrm{f}}\right)$ was sandwiched in between a pair of aluminum (Al) membrane disks with an equal-diameter of $2.35 \mathrm{~cm}$, forming a proton-sensing Al-Tf-Al membrane assembly. This assembly was then fit with the small Teflon center chamber (Figure 2c). In addition, pieces of proton-sensing $\mathrm{Al}$ film were placed on the water surfaces $\left(\mathrm{P}_{\mathrm{s}}\right.$ and $\left.\mathrm{Ns}\right)$, and more importantly into the water bulk-water phase $\left(\mathrm{P}_{B}\right.$ and $\left.\mathrm{N}_{\mathrm{B}}\right)$ near the middle of both the anode and cathode water chambers (Figures 1 and $2 \mathrm{a})$ to track the distribution of the created excess protons.

After the apparatus was set up as shown in (Figure 1), $200 \mathrm{~V}$ of electrolysis voltage was applied to the system for 10 hours using a Source Voltage/digital multi-meter system (Keithley instruments series 2400S-903-01 Rev E). The resulting electric current was measured as a function of time using the digital multi-meter interfaced with a PC computer using LabVIEW software. The area under the current versus time curve was integrated using Originpro 8.6 and LabVIEW program (detailed procedure in SI Materials and Methods).

\section{Results and Discussion}

\section{Localized excess protons demonstrated with a proton-sensing} film

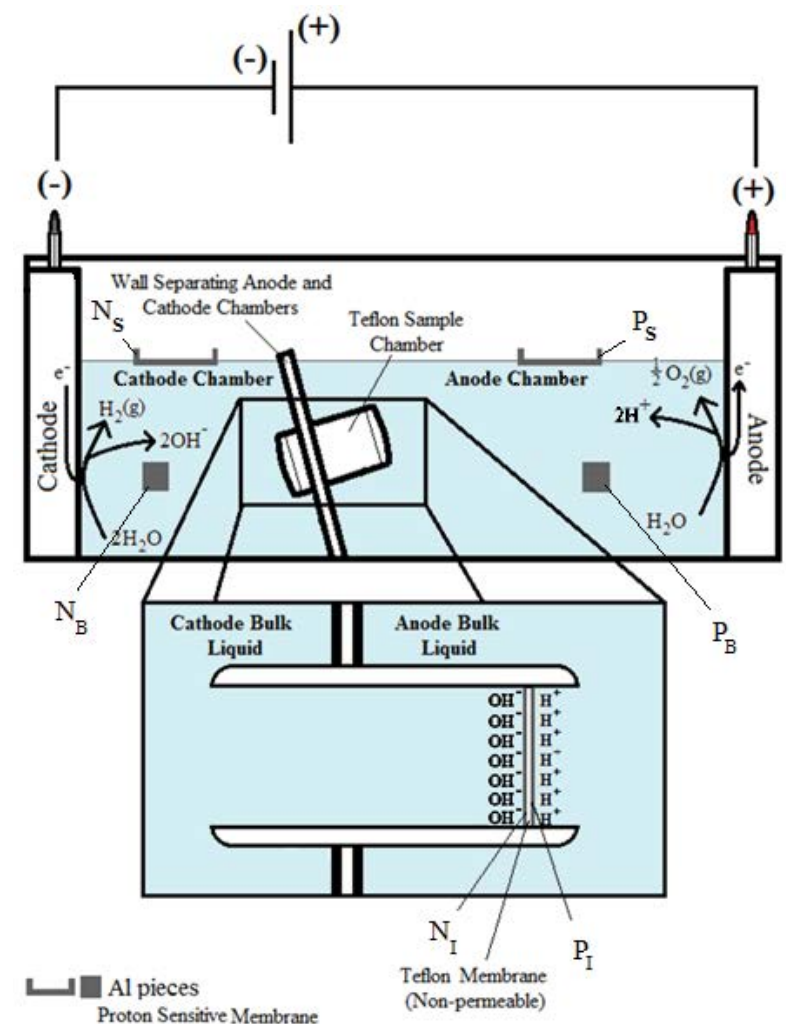

Figure 1: Illustration on how excess protons and excess hydroxyl anions were generated by utilizing an ElectroPrep "open-circuit" water-electrolysis system comprising a cathode chamber, a Teflon center chamber assembly, and an anode chamber. The excess protons in the anode water were electrostatically localized at water-membrane interface $\left(P_{1}\right)$ along the membrane surface while the excess hydroxyl anions in the cathode water chamber (at the left) were electrostatically attracted to the water-membrane interface $\left(\mathrm{N}_{1}\right)$ on the other side of membrane, forming a "hydroxyl anions-membrane-excess protons" capacitor-like system (see Inset). Pieces of proton-sensitive Al films were applied on the anode water surface $\left(P_{\mathrm{S}}\right)$, the cathode water surface $\left(\mathrm{N}_{\mathrm{S}}\right)$, in the middle of the anode chamber water bulk phase $\left(P_{B}\right)$ and in the middle of the cathode chamber water bulk phase $\left(N_{B}\right)$
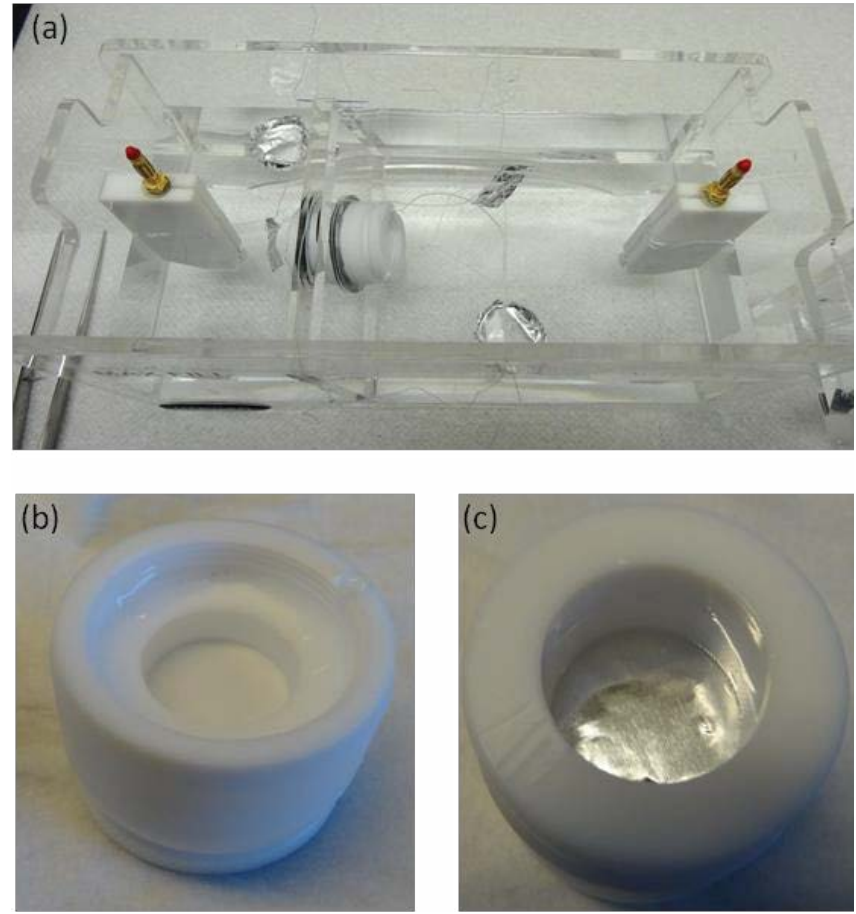

Figure 2: (a) A top view photograph showing the ElectroPrep apparatus. Pieces of proton-sensitive films were applied on the water surface and in the middle (bulk phase) of both the anode and cathode water chambers. Nylon strings were used to anchor the pieces of proton-sensitive films that were suspended in the middle of both the anode and cathode water chambers. (b) Teflon center chamber assembly with a Tf-Al-Tf membrane. (c) Teflon center chamber assembly with a proton-sensing Al-Tf-Al membrane.

During the open-circuit electrolysis of ultrapure water, excess protons were produced in the anode $(\mathrm{P})$ chamber while excess hydroxyl anions were generated in the cathode $(\mathrm{N})$ chamber (Figure 1). According to the proton-electrostatics localization hypothesis, the free excess protons in the anode water body would not stay in the bulk liquid phase; they would localize to the water-membrane (Teflon) interface (the $\mathrm{P}_{\mathrm{I}}$ site) in the anode $(\mathrm{P})$ chamber and attract the excess hydroxyl ions of the cathode water body to the $\mathrm{N}_{\mathrm{I}}$ site at the other side of the membrane, forming an "excess anions-membrane-excess protons" capacitor-like system (as shown in the inset of Figure 1). According to this prediction, the bulk $\mathrm{pH}$ in either the anode water body or the cathode water body would not be affected by the excess protons or the excess hydroxyl ions created by the water electrolysis process. These predicted features were indeed observed in this experimental study. It is known that aluminum surface can begin to be corroded by protons when the effective proton concentration is above $0.1 \mathrm{mM}$ (equivalent to a $\mathrm{pH}$ value below 4) $[32,33]$. This property was therefore employed as a proton-sensing mechanism in combination with the bulk phase $\mathrm{pH}$ electrode measurement to determine the distribution of excess protons in the water-membrane-water system (Figure 1). In the first set of experiments (performed in triplicate), small pieces of aluminum film were employed as a proton sensor at a number of locations in both of the water chambers to serve as an indicator for the excess protons. As illustrated in Figures 1 and 2c, a Teflon membrane (Tf) was sandwiched in between two pieces of aluminum film (Al), forming a proton-sensing Al-Tf-Al membrane system that separate the two water bodies: the cathode water body on the left and the anode water body on the right. The result of the "cathode water Al-Tf-Al water anode" 
experiment showed that only the proton-sensing film placed at the $P_{I}$ site facing the anode liquid showed proton-associated corrosion (see the dark brownish grey on the exposed part of the proton-sensing film in Figure 3) while the proton-sensing film placed in the bulk liquid phase $\left(\mathrm{P}_{\mathrm{B}}\right)$ of the anode chamber or floated on the top surface $\left(\mathrm{P}_{\mathrm{S}}\right)$ of the anode water body showed no proton-associated corrosion activity. This is a significant observation since it indicates that excess protons are localized primarily along the water-membrane interface at the $\mathrm{P}_{\mathrm{I}}$ site, but not in the bulk liquid phase $\left(\mathrm{P}_{\mathrm{B}}\right)$. This observation agrees with the proton-electrostatics localization hypothesis perfectly. Also as expected, all pieces of proton-sensing film placed at the $\mathrm{N}_{\mathrm{I}}, \mathrm{N}_{\mathrm{B}}$, and $\mathrm{N}_{\mathrm{S}}$ sites of the cathode liquid showed no-proton-associated corrosion activity as well.

According to the Mitchellian proton delocalized view, the excess protons in a water body would behave like a solute such as a sugar molecule which can stay anywhere in the liquid including its bulk liquid phase. Certain commonly heard arguments in favor of the Mitchellian proton delocalized view even as of today seem still believe that the excess protons would behave like solutes that could delocalize into the bulk liquid phase somehow by "proton solvation" or "electro diffusion". If that delocalized view is true, it would predict that all the proton-sensing films in the anode water chamber including the one placed in the bulk liquid $\left(\mathrm{P}_{\mathrm{B}}\right)$ should be able to detect the excess protons. The observation that the proton sensor placed into the anode chamber bulk water phase $\left(\mathrm{P}_{\mathrm{B}}\right)$ could not detect any excess protons while the proton sensor placed at the $\mathrm{P}_{\mathrm{I}}$ site showed proton-associated aluminum corrosion activity clearly rejects the Mitchellian proton delocalized view.

\section{Result of bulk-phase $\mathrm{pH}$ measurements}

During a 10-hour experiment with 200V-driven water electrolysis, it was noticed, as expected, the formation of small gas bubbles at both the anode and cathode platinum electrodes. This observation is consistent with the well-known water electrolysis process in which
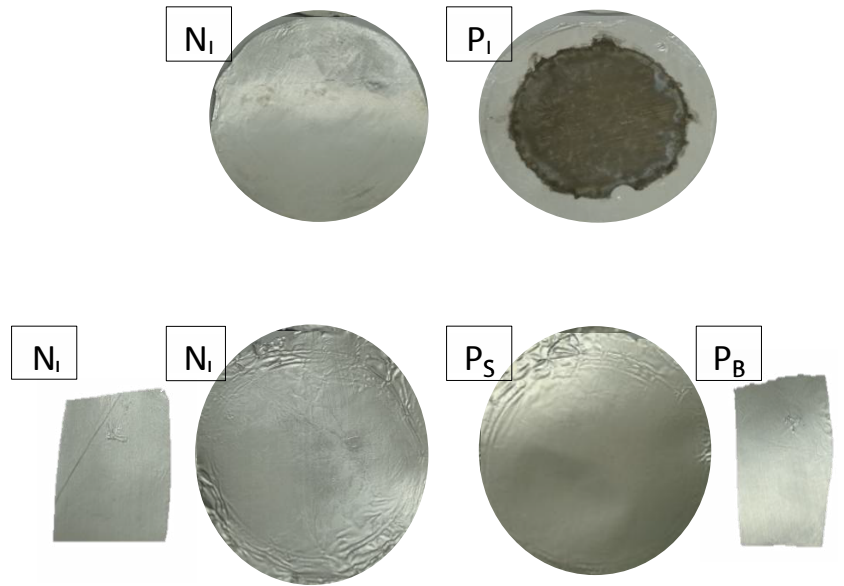

Figure 3: Observations with proton-sensing Al films after 10 hours of cathode water Al-Tf-Al water anode experiment with water electrolysis $(200 \mathrm{~V})$. $\mathrm{N}_{\mathrm{f}}$ : Proton-sensing film at the $\mathrm{N}$ side of Teflon membrane detected no proton activity. $\mathrm{P}_{i}$ : Proton-sensing film at the $\mathrm{P}$ side of Teflon membrane detected dramatic activity of localized protons (dark grey color). $\mathrm{N}_{\mathrm{B}}$ : Proton-sensing film suspended inside the water of the cathode chamber. $N_{S}$ : Proton-sensing film floating on the water surface of cathode chamber. $P_{s}$ : Proton-sensing film floating on the water surface of anode chamber. $P_{B}$ : Proton-sensing film suspended inside the water of the anode chamber. water is electrolytically oxidized to molecular oxygen (gas) producing protons in the anode water compartment while protons are reduced to molecular hydrogen (gas) leaving more hydroxyl anions in the cathode water compartment. If the Mitchellian proton delocalized view is true, it would predict that the production of excess protons in the anode water compartment would result in a lower $\mathrm{pH}$ value for the bulk water body while the generation of excess hydroxyl anions in the cathode water body would result in a higher $\mathrm{pH}$ in its bulk water body. That is, if the proton delocalized view is true, it would predict a significant bulkphase $\mathrm{pH}$ difference $(\Delta \mathrm{pH})$ between the anode and the cathode water bodies. Our experimental result with the bulk-phase $\mathrm{pH}$ measurements demonstrated that the Mitchellian proton delocalized view is not true. As shown in Table 1, after the 10-hour experiment with the water AlTf-Al (membrane) water system, the measured $\mathrm{pH}$ value in the anode bulk water body $(5.76 \pm 0.09)$ remained essentially the same as that of the cathode bulk water phase $(5.78 \pm 0.14)$. These bulk water phase $\mathrm{pH}$ values averaged from 3 replication experiments (each replication experiment with at least 6 reading of $\mathrm{pH}$ measurement in each chamber water, $\mathrm{n}=3 \times 6=18)$ were statistically also the same as those $(5.78 \pm 0.04$ and $5.76 \pm 0.02)$ in the control experiments in absence of the water electrolysis process. This is a significant experimental observation since it confirmed the prediction of the proton-electrostatics localization hypothesis that the excess protons do not stay in the bulk water phase and thus cannot be measured by a $\mathrm{pH}$ electrode in the bulk phase.

This observation can also explain why in certain bioenergetic system such as thylakoids where ATP synthesis through photophosphorylation sometimes can occur without measurable $\Delta \mathrm{pH}$ across the thylakoid membrane between the two bulk aqueous phases [9]. As shown in the present study, although the bulk-phase $\mathrm{pH}$ difference $(\Delta \mathrm{pH})$ between the anode chamber water and the cathode chamber water is zero, the excess protons were localized at the water-membrane interface as demonstrated by the dramatic proton activity on the proton-sensing film placed at the $\mathrm{P}_{\mathrm{I}}$ site (Figure 3). This indicated that the concentration of localized excess protons was much higher than $0.1 \mathrm{mM}$.

Furthermore, the measured $\mathrm{pH}$ value of $5.76 \pm 0.09$ in the anode bulk water phase was also consistent with the observation that the piece of proton-sensing film placed in the anode bulk water phase $\left(\mathrm{P}_{\mathrm{B}}\right)$ showed no sign of proton-associated corrosion activity while the proton-sensing film placed at $\mathrm{P}_{\mathrm{I}}$ site had dramatic proton-associated corrosion (Figure 3 ). This indicated that the generated excess protons are localized primarily at the water-membrane interface at the $\mathrm{P}_{\mathrm{I}}$ site resulting in a proton surface density that is high enough $(\mathrm{pH}<4)$ to cause the aluminum corrosion there.

The $\mathrm{pH}$ measurements also showed that the freshly deionized water had an average $\mathrm{pH}$ value of $6.89 \pm 0.03$ before being used in the experiments (Table 1). Since the experiments were conducted with the laboratory ambient air conditions, the gradual dissolution of atmospheric $\mathrm{CO}_{2}$ into the deionized water during a 10-hour experiment period resulted in water $\mathrm{pH}$ change from $6.89 \pm 0.03$ to 5.68 \pm 0.06 , which was observed in the control experiment with the same "cathode water Al-Tf-Al water anode" setup except without turning on the electrolysis voltage $(0 \mathrm{~V})$. Therefore, this bulk water $\mathrm{pH}$ change had little to do with the $200 \mathrm{~V}$-driven water electrolysis process. The same magnitude of bulk water $\mathrm{pH}$ change before and after the experiment was observed for the deionized water in both the anode and cathode chambers, which also supports the understanding that this bulk water $\mathrm{pH}$ change from the beginning to the end of the experiment was due to the gradual dissolution of atmospheric $\mathrm{CO}_{2}$ into the deionized water during the 10-hour experiment period. There was no difference between 


\begin{tabular}{|c|c|c|c|}
\hline \multicolumn{2}{|c|}{ Experiments } & pH of cathode water & pH of anode water \\
\hline \multirow{2}{*}{ With (Al-Tf-Al) 200 V V } & Before & $6.89 \pm 0.03$ & $6.89 \pm 0.03$ \\
\cline { 2 - 4 } & After & $5.78 \pm 0.14$ & $5.76 \pm 0.09$ \\
\hline \multirow{2}{*}{\begin{tabular}{c} 
With (Tf-Al-Tf) 200 V V \\
\cline { 2 - 4 }
\end{tabular}} & Before & $6.71 \pm 0.10$ & $6.71 \pm 0.10$ \\
\hline $\begin{array}{c}\text { With (Al-Tf-Al) } \\
\text { control (OV) }\end{array}$ & Before & $5.81 \pm 0.04$ & $5.76 \pm 0.03$ \\
\hline $\begin{array}{c}\text { With (Tf-Al-Tf) } \\
\text { control (OV) }\end{array}$ & After & $5.68 \pm 0.03$ & $6.89 \pm 0.03$ \\
\hline & Bfter & $6.71 \pm 0.10$ & $5.78 \pm 0.02$ \\
\hline
\end{tabular}

Table 1: Averaged $\mathrm{pH}$ values measured in bulk water phase before and after 10 hours experiment with cathode water membrane water anode systems.

${ }^{*}$ The averaged $\mathrm{pH}$ values and standard deviation ( \pm sign) were calculated from the original data of bulk water phase $\mathrm{pH}$ measurements presented in detail in the Support Information document (Tables S1a, S1b, S2a, S2b, S3a and S3b) (Supplementary File).

the bulk-phase $\mathrm{pH}$ of anode chamber water ( $\mathrm{pH} 5.76 \pm 0.09)$ and that of the cathode chamber water $(5.78 \pm 0.14)$ at the end of the experiment. This result also points to the same underline understanding that the excess protons do not behave like typical solute molecules. Excess protons do not stay in the water bulk phase; they localize at the watermembrane interface at the $\mathrm{P}_{\mathrm{I}}$ site so that they cannot be detected by the bulk-phase $\mathrm{pH}$ measurement.

A further set of experiments with the setup of "cathode water Tf-Al-Tf water anode" was also conducted in triplicate. In this set of experiments, Tf-Al-Tf membrane system was used instead of the Al-Tf$\mathrm{Al}$ membrane system. Since the Teflon membrane is chemically inert to protons, the use of the Tf-Al-Tf membrane system eliminated the consumption of excess protons by the aluminum corrosion process at the $\mathrm{P}_{\mathrm{I}}$ site that was demonstrated above. In this set of the experiments, no bulk-phase $\mathrm{pH}$ difference $(\Delta \mathrm{pH})$ between the anode and cathode water bodies was observed as well. As shown in Table 1, after 10 hours run at $200 \mathrm{~V}$ with the "cathode water Tf-Al-Tf water anode" system, the measured $\mathrm{pH}$ value in the anode bulk water phase $(5.76 \pm 0.03)$ was essentially the same as that of the cathode bulk water phase $(5.81 \pm 0.04)$. This experimental observation again indicated that the excess protons do not stay in the bulk water phase and thus cannot be measured by the bulk liquid phase $\mathrm{pH}$ measurement. Since liquid water is an effective proton conductor as discussed above, the excess protons produced in the anode water compartment electrostatically localize to the water-membrane interface at the $\mathrm{P}_{\mathrm{I}}$ site.

\section{Excess protons assessed with water electrolysis electric current}

The proton-charging-up process in this "excess hydroxyl anions Tf-Al-Tf excess protons" capacitor system was monitored by measuring the electric current of the $200 \mathrm{~V}$-driven water electrolysis process as a function of time during the entire 10-hour experimental run. The data in the inset of Figure 4 showed that the electric current of the water electrolysis process decreased with time as expected. That is, when the excess protons were generated in the anode water compartment (while the excess hydroxyl anions were generated in the cathode water compartment), this "excess hydroxyl anions Tf-Al-Tf excess protons" capacitor is being charged up by localization of the excess protons at the $\mathrm{P}_{\mathrm{I}}$ site and the excess hydroxyl anions at $\mathrm{N}_{\mathrm{I}}$ site (Figure 1). According to our analysis, this process reached thermodynamic equilibrium after about 1500 seconds (shown in the inset of Figure 4) under this experimental condition where the curve of the water electrolysis current quickly became flat indicating the completion of the water electrolysis-coupled proton-charging-up process.

By calculating the area under the water-electrolysis current curve

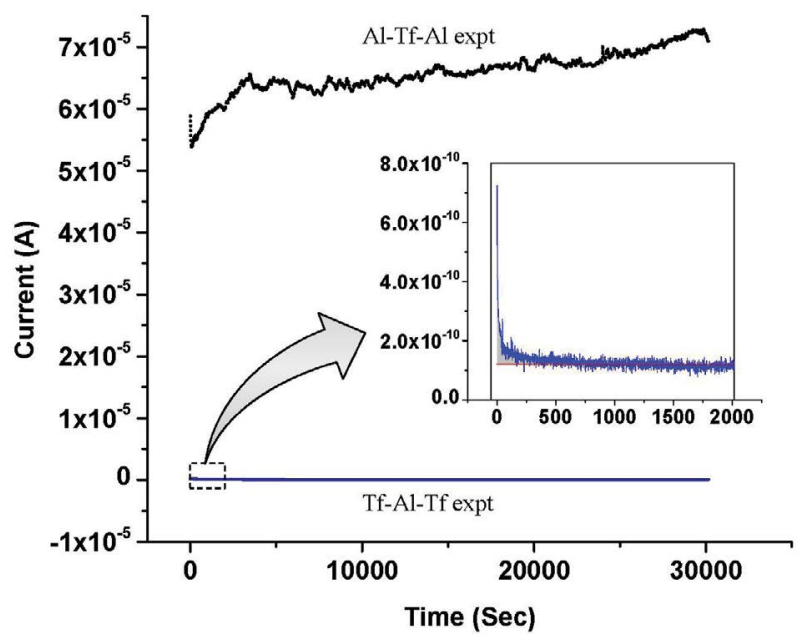

Figure 4: The electric current of water electrolysis measured as a function of time with $200 \mathrm{~V}$ during 10 hours experimental run. The black curve shows average of three experiments with "cathode water Al-Tf-Al water anode". The blue line shows average of three experiments with "cathode water Tf-Al-Tf water anode"; and its initial part within the first 2000 seconds is plotted in an expanded scale showing the integration for the area under the curve (Inset).

above the flat baseline as shown in the inset of Figure 4, the amount of excess protons loaded onto the "excess hydroxyl anions Tf-AlTf excess protons" capacitor was estimated to be $2.98 \times 10^{13}$ moles (Supplementary Table S5a). The area of the Teflon membrane surface exposed to the anode water at the $\mathrm{P}_{\mathrm{I}}$ site was measured to be $2.55 \mathrm{~cm}^{2}$. If that amount of excess protons were loaded at the $\mathrm{P}_{\mathrm{I}}$ site onto the Teflon membrane surface exposed to the anode water, the maximal localized excess proton density per unit area was estimated to be 1.19 nanomoles $\mathrm{H}^{+} / \mathrm{m}^{2}$. Although the exact thickness of the localized excess proton layer at the $\mathrm{P}_{\mathrm{I}}$ site is yet to be determined, our recent study [28] indicated that the effective thickness for this type of the electrostatically localized excess proton layer may be about $1 \pm 0.5 \mathrm{~nm}$. If that is the case, then the localized excess proton density of 1.19 nanomoles $\mathrm{H}^{+} /$ $\mathrm{m}^{2}$ would translate to a localized excess proton concentration of 1.19 $\mathrm{mM} \mathrm{H}^{+}$(equivalent to a localized $\mathrm{pH}$ value of 2.92 as calculated in SI) at the $\mathrm{P}_{\mathrm{I}}$ site, which can explain why they can be detected by the protonsensing $\mathrm{Al}$ film there.

The water electrolysis current in the "cathode water Al-Tf-Al water anode" experiment was also monitored. As shown in Figure 4, after about 5000 seconds, the water electrolysis electric current at the steady state of this experiment reached around $6.5 \times 10^{-5} \mathrm{~A}$, which was much bigger than that (below $1 \times 10^{-10} \mathrm{~A}$ ) of the "cathode water Tf-Al-Tf water anode" experiment. This large water electrolysis electric current can be attributed to the consumption of excess protons by the proton-sensing Al film at the $\mathrm{P}_{\mathrm{I}}$ site. As the proton-sensing film at the $\mathrm{P}_{\mathrm{I}}$ site consumes the excess protons, more excess protons can then be produced at the anode electrode, resulting in a significant water-electrolysis electric current. The high concentration of the electrostatically localized excess protons at the $P_{I}$ site thermodynamically drives the aluminum corrosion reaction in which aluminum atoms are oxidized by protons resulting in evolution of molecular hydrogen gas. During the experiment, we indeed noticed the formation of gas bubbles on the aluminum membrane surface at the $\mathrm{P}_{\mathrm{I}}$ site (Figure $\mathrm{S} 2$ ).

By calculating the area under the water-electrolysis current curve from the "cathode water Al-Tf-Al water anode" experiment 
Citation: Saeed HA, Lee JW (2015) Experimental Demonstration of Localized Excess Protons at a Water-Membrane Interface. Bioenergetics 4: 127. doi:10.4172/2167-7662.1000127

Page 6 of 7

and subtracting that of the "cathode water Tf-Al-Tf water anode" experiment, we were able to calculate the amount of excess protons that were generated by the anode and consumed by the proton-sensing film at the $\mathrm{P}_{\mathrm{I}}$ site. As shown in Supplementary Table S5b, during the 10$\mathrm{hr}$ "cathode water Al-Tf-Al water anode" experiment, a total of $2.11 \mathrm{x}$ $10^{-5}$ moles of excess protons were generated by the anode platinum electrode. These excess protons were apparently translocated to the proton sensing film surface at the $\mathrm{P}_{\mathrm{I}}$ site and consumed there by the corrosion reaction as shown in Figure $3 \mathrm{~b}$. The amount of protons consumed per unit area was calculated to be $8.29 \times 10^{-6}$ moles per $\mathrm{cm}^{2}$.

\section{Conclusion}

The experimental results reported above clearly demonstrated that excess protons were localized at the water-membrane interface in the anode water-membrane-water cathode system. The most remarkable evidence for the localized excess protons came from the observation that the proton-sensing film placed at the $\mathrm{P}_{\mathrm{I}}$ site of Teflon membrane showed dramatic excess proton activity (corrosion) while the protonsensing film placed into the anode chamber water bulk phase $\left(\mathrm{P}_{\mathrm{B}}\right)$ showed no proton activity during the entire experiment. The density of localized excess protons created in this experiment was estimated to be about $1.19 \mathrm{mM} \mathrm{H}^{+}$(pH value of 2.92) at the water-membrane interface $\left(\mathrm{P}_{\mathrm{I}}\right.$ site), which explains why it can be sensed by the protonsensing $\mathrm{Al}$ membrane. Furthermore, the bulk-phase $\mathrm{pH}$ measurements in both anodic and cathodic water chambers also confirmed that excess protons do not stay in the bulk aqueous phase, which clearly rejects the Mitchellian proton delocalized view. These observations clearly match with the predictions from the proton-electrostatics localization hypothesis: excess protons do not stay in the water bulk phase; they localize at the water-membrane interface in a manner similar to the behavior of excess electrons in a conductor. This finding has significance not only in the science of bioenergetics but also in the fundamental understanding for the importance of water to life. It is now quite clear that water serves not only as a solvent and substrate but also as a proton conductor for proton coupling energy transduction in living organisms.

Furthermore, the localized excess protons that have now been demonstrated for the first time through this research may have practical implications as well. For example, the utilization of localized excess protons that can be created in pure water may lead to clean "green chemistry" technologies for industrial applications such as metal acid washing and/or protonation of certain micro/nanometer materials without requiring the usage of conventional acid chemicals such as nitric and sulfuric acids.

\section{Author Contributions}

J.W.L. designed research and experiments, analyzed data, and wrote the article; H.A.S. performed experiments, analyzed data and wrote the article under the guidance of J.W.L.

\section{Acknowledgement}

The authors wish to thank Dr. Donald Richard Ort, a world-class Bioenergetics expert, for his valuable discussions and reading of this manuscript. This work was supported in part with the Lee laboratory start-up research funds that were provided by the Department of Chemistry and Biochemistry, the College of Sciences, the Office of Research at Old Dominion University, and by the Old Dominion University Research Foundation.

\section{Supporting Information}

Supporting information for this article is available on-line at the journal website. The supporting information describes: (1) Detailed materials and methods; (2) Localized excess protons demonstrated with a proton-sensing film; (3) Result of bulk-phase pH measurements; (4) Excess protons assessed with water electrolysis electric current; and (5) Experimental calculation of proton density.

\section{References}

1. Mitchell $P$ (1961) Coupling of phosphorylation to electron and hydrogen transfer by a chemi-osmotic type of mechanism. Nature 191: 144-148.

2. Mitchell $P$ (1976) Possible molecular mechanisms of the protonmotive function of cytochrome systems. J Theor Biol 62: 327-367.

3. Mitchell P (1978) David Keilin's respiratory chain concept and its chemiosmotic consequences. Nobel Prize lecture 1: 295-330.

4. Garrett R, Grisham C (2013) Biochemistry Books. (5thedn) Cole, Cengage learning.

5. Nelson DL, Lehninger AL, Cox MM (2013) Lehninger principles of biochemistry (6thedn) Macmillan.

6. Nicholls DG, Ferguson S (1992) Bioenergetics 2. New York: Academic Press.

7. Mitchell $P$ (2011) Chemiosmotic coupling in oxidative and photosynthetic phosphorylation. 1966. Biochim Biophys Acta 1807: 1507-1538.

8. Junge W (2013) Half a century of molecular bioenergetics. Biochem Soc Trans 41: $1207-1218$.

9. Vinkler C, Avron M, Boyer PD (1978) Initial formation of ATP in photophosphorylation does not require a proton gradient. FEBS Letters 96: 129-134.

10. Ferguson SJ (1985) Fully delocalised chemiosmotic or localised proton flow pathways in energy coupling? A scrutiny of experimental evidence. Biochimica et Biophysica Acta (BBA)-Reviews on Bioenergetics 811: 47-95.

11. Dilley RA, Theg SM, Beard WA (1987) Membrane-proton interactions in chloroplast bioenergetics: Localized proton domains. Annual review of plant physiology 38: 347-389.

12. Dilley RA (2004) On why thylakoids energize ATP formation using either delocalized or localized proton gradients $\mathrm{Ca} 2+$ mediated role in thylakoid stress responses. Photosynthesis research 80: 245-263.

13. Williams RJ (2011) Chemical advances in evolution by and changes in use of space during time. J Theor Biol 268: 146-159.

14. Williams RJ (1975) Proton-driven phosphorylation reactions in mitochondria and chloroplast membranes. FEBS Lett 53: 123-125.

15. Mulkidjanian AY, Heberle J, Cherepanov DA (2006) Protons @ interfaces: implications for biological energy conversion. Biochim Biophys Acta 1757: 913930

16. Krulwich TA (1986) Bioenergetics of alkalophilic bacteria. J Membr Biol 89: 113 125.

17. Krulwich TA, Guffanti AA (1989) Alkalophilic bacteria. Annual Reviews in Microbiology 43: 435-463.

18. Olsson K, Keis S, Morgan HW, Dimroth P, Cook GM (2003) Bioenergetic properties of the thermoalkaliphilic Bacillus sp. strain TA2.A1. J Bacteriol 185 461-465.

19. Sturr MG, Guffanti AA, Krulwich TA (1994) Growth and bioenergetics of alkaliphilic Bacillus firmus OF4 in continuous culture at high $\mathrm{pH}$. J Bacteriol 176: 3111-3116.

20. Krulwich TA (1995) Alkaliphiles: 'basic' molecular problems of $\mathrm{pH}$ tolerance and bioenergetics. Mol Microbiol 15: 403-410.

21. Padan E, Bibi E, Ito M, Krulwich TA (2005) Alkaline $\mathrm{pH}$ homeostasis in bacteria: new insights. Biochim Biophys Acta 1717: 67-88.

22. Guffanti AA, Krulwich TA (1984) Bioenergetic problems of alkalophilic bacteria. Biochem Soc Trans 12: 411-412.

23. Krulwich TA, Ito M, Gilmour R, Hicks DB, Guffanti AA (1998) Energetics of alkaliphilic Bacillus species: physiology and molecules. Adv Microb Physiol 40: 401-438.

24. Krulwich TA (2011)Adaptive mechanisms of extreme alkaliphiles. Extremophiles handbook 119-139.

25. Guffanti AA, Krulwich TA (1988) ATP synthesis is driven by an imposed delta pH 
Citation: Saeed HA, Lee JW (2015) Experimental Demonstration of Localized Excess Protons at a Water-Membrane Interface. Bioenergetics 4: 127. doi:10.4172/2167-7662.1000127

Page 7 of 7

or delta mu $\mathrm{H}+$ but not by an imposed delta $\mathrm{pNa}+$ or delta mu $\mathrm{Na}+$ in alkalophilic Bacillus firmus OF4 at high pH. J Biol Chem 263: 14748-14752.

26. Guffanti AA, Hicks DB (1991) Molar growth yields and bioenergetic parameters of extremely alkaliphilic Bacillus species in batch cultures, and growth in a chemostat at $\mathrm{pH}$ 10.5. Journal of general microbiology 137: 2375-2379.

27. Lee J (2012) Proton-electrostatics hypothesis for localized proton coupling bioenergetics. Bioenergetics 1: 2

28. Lee J (2015) Proton-electrostatic localization: explaining the bioenergetic conundrum in alkalophilic bacteria. Bioenergetics 4 .
29. Marx D (1999) The nature of the hydrated excess proton in water. Nature 397 601-604.

30. Pomès R, Roux B (2002) Molecular mechanism of $\mathrm{H}+$ conduction in the singlefile water chain of the gramicidin channel. Biophys J 82: 2304-2316.

31. Marx D (2006) Proton transfer 200 years after von Grotthuss: insights from ab initio simulations. Chemphyschem 7: 1848-1870.

32. Pourbaix M (2006) Applications of electrochemistry in corrosion science and in practice. Corrosion Science 14: 25-82.

33. Pourbaix M (1974) Atlas of electrochemical equilibria in aqueous solutions. 